\title{
Clinically Relevant Postoperative Pancreatic Fistula rates in two methods of pancreatico-jejunal anastomosis compared: Evolution of surgical technique in a single centre over time
}

\section{Tommaso Zurleni ( $\nabla$ tzurleni@yahoo.it )}

ASST Valle Olona, Hospital of Busto Arsizio https://orcid.org/0000-0002-3971-2297

Simone Olmetti

Ospedale di Busto Arsizio

Luca Marzoli

Ospedale di Busto Arsizio

Francesco Zurleni

Ospedale di Busto Arsizio

\section{Research article}

Keywords: pancreatico-jejunal anastomosis, pancreatic cancer, postoperative pancreatic fistula, pancreaticoduodenectomy, pancreatic surgery, duct-to-mucosa anastomosis

Posted Date: May 8th, 2020

DOI: https://doi.org/10.21203/rs.3.rs-24483/v1

License: (c) (1) This work is licensed under a Creative Commons Attribution 4.0 International License.

Read Full License 


\section{Abstract}

Background:

Pancreaticoduodenectomy remains the gold standard for management of patients with pancreatic head and periampullary neoplasms. Despite the low mortality, overall morbidity remains high, principally due to the development of a clinically relevant postoperative pancreatic fistula (CR-POPF).

The aim of the present study is to compare rates of CR-POPF in two groups of patients treated with two different pancreaticojejunostomy techniques.

Methods:

Among 264 consecutive patients submitted to surgery for pancreatic neoplasm, 142

pancreaticoduodenectomies with end-to-side pancreaticojejunostomy were analysed. The first group of patients underwent a direct mucosa-to-mucosa anastomosis as described by Longmire and Traverso. In the second group, a duct-to-mucosa anastomosis with an outer seromuscolar and inner full thickness layer as described by Z'graggen, Shrikhande and Buchler was performed.

Results:

Mortality was $2,8 \%$ in the first group $(2 / 71)$ and zero in the second. In group $1^{\circ}, 48.5 \%$ of patients suffered one or more grade II-V Clavien-Dindo complications; in group $2^{\circ}$, complications were observed in $26,7 \%$ of patients. Clinically relevant POPF occurred in 12 patients in group $1^{\circ}(17 \%)$ and in 4 patients in group $2^{\circ}$ $(5,6 \%)$.

Conclusions:

Changing pancreaticojejunostomy techniques may produce different outcomes. In our experience, a standardized duct-to-mucosa anastomosis, as performed in group 2 , significantly reduced the rate of CRPOPF.

\section{Background}

Pancreaticoduodenectomy (PD) is considered the standard treatment for malignant and benign lesions of the pancreatic head and periampullary region. It is a technically challenging procedure requiring a high level of surgical experience with regard to resection and reconstruction.

Whereas the rate of mortality associated with PD has dramatically decreased in the last two decades to below $5 \%$, the morbidity rate remains high, from $30-50 \%$, indicating the complexity of pancreatic surgery [1]. The most important and potentially life-threatening complication after PD is the occurrence of a postoperative pancreatic fistula (POPF), traditionally perceived as the Achilles heel. From the literature, its 
incidence varies from $2 \%$ to more than $20 \%$ [2-4]. In 2005, the International Study Group of Pancreatic Fistula (ISGPF) reached a consensus, defining a clinical system of 3 grades of POPF: A, B and C [5].

Afterwards, criticism was published until the International Study Group of Pancreatic Surgery (ISGPS) in 2017 introduced a new definition on the grading of POPF [6-8]. Grade A is now redefined as "biochemical leak"; grades B and C (clinically relevant POPF) are confirmed but defined more strictly: patients who required percutaneous drains are classified as grade $B$, while those classified as grade $C$ are associated with organ failure, reoperation or death [8].

The aim of the present study is to compare the rate of clinically relevant POPF in two groups of patients before and after the introduction of a standardized technique of pancreaticojejunal anastomosis described by Z'graggen, Shrikhande and Buchler $[9,10]$.

\section{Methods}

\section{Patients}

From January 2000 to December 2015, of 264 consecutive patients (of which 37 were admitted for palliative or exploratory procedures), 227 underwent pancreatic surgery in our centre. These included 142 cephalic pancreatoduodenectomy (PD), 14 total duodenopancreatectomy, 3 central resection, 4 pancreaticojejunal derivation in pseudocyst, 38 distal pancreatectomy with or without splenectomy, and 26 multiorgan resection including corpo-caudal pancreatectomy for infiltrating neoplasia from stomach, colon and left kidney or retroperitoneal sarcoma.

None of the patients underwent neoadjuvant treatment.

Of the 142 PD, 71 consecutive patients underwent surgery before March 2009 (Group 1); the other 71 patients were enrolled from April 2009 (group 2) after introduction of a different technique for pancreatic anastomosis. The clinicopathological characteristics of the two groups are shown in Table 1. 
Table 1

Clinicopathological characteristics

\begin{tabular}{|c|c|c|c|}
\hline & Group $1^{\circ}(\%)$ & Group $2^{\circ}(\%)$ & p-value \\
\hline $\mathrm{N}^{\circ}$ of patients & 71 & 71 & \\
\hline $\operatorname{Sex}(M / F)$ & $36 / 35$ & $38 / 33$ & 0.74 \\
\hline Age & 65 & 66 & \\
\hline$A S A \geq 2$ & $65(92)$ & $65(92)$ & 1 \\
\hline Malignant disease & $66(93)$ & $65(92)$ & 0.75 \\
\hline Pancreas & $36(51)$ & $50(70)$ & \\
\hline Ampullar & $25(35)$ & $14(20)$ & \\
\hline Distal biliary duct & $5(7)$ & $6(8)$ & \\
\hline Others & $5(7)$ & $1(1.4)$ & \\
\hline Benign disease & $5(7)$ & $6(8)$ & \\
\hline Type of resection & & & 0.35 \\
\hline PD classic Whipple & $18(25)$ & $23(32)$ & \\
\hline PPPD Pylorus preserving PD & $53(75)$ & $48(68)$ & \\
\hline Vascular resection & $3(4)$ & $12(17)$ & 0.026 \\
\hline Pancreatic duct diameter $<3 \mathrm{~mm}$ & $15(21)$ & $18(25)$ & 0.55 \\
\hline Pancreatic texture & Not routinely collected & Not routinely collected & \\
\hline Preoperative biliary drainage (PBD) & $28(39)$ & $37(52)$ & 0.13 \\
\hline T tube Kehr & $65(91)$ & $5(7)$ & $<0.001$ \\
\hline Internal p-j stent & $34(47)$ & $1(1.4)$ & $<0.001$ \\
\hline
\end{tabular}

\section{Surgery}

All patients underwent open surgical procedure.

In group 1, a pancreaticojejunostomy described by Longmire and Traverso [11] "as a direct mucosa-tomucosa anastomosis of the pancreatic duct to the jejunum" was performed. Posterior and anterior layers were constituted of 4.0 interrupted stitches and mucosa to mucosa with 6.0 poliglicolic monofilament splinted in $47 \%$ of cases with an internal stent.

Then, an end-to-side hepaticojejunostomy was splinted (91\% of cases) with a T tube inserted through the bile duct. 
The surgical technique of Group $2^{\circ}$ was previously described by Z'graggen, Shrikhande and Buchler "as end to side duct to mucosa anastomosis with an outer seromuscolar and inner full thickness layer" [9, 10]. The cut end of the left hemipancreas was mobilized for $2 \mathrm{~cm}$ to allow the placement of a posterior external suture. All stitches were monofilament absorbable PDS 5 - 0 (C-1, $13 \mathrm{~mm} 3 / 8 \mathrm{c}$, visi-black, or TF

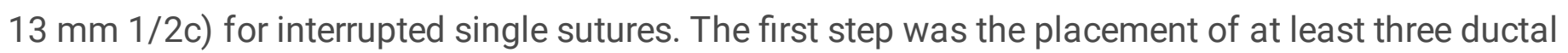
sutures, first anterior and then posterior, including the cut edge of the pancreas remnant; the ductal stitches were retained with clamps and organized in order.

The anastomosis consisted of two posterior row, external and inner sutures, and two anterior, inner and external sutures. External posterior suture was performed with interrupted suture every 4-5 $\mathrm{mm}$ placed from the dorsal pancreatic capsule and parenchyma to the jejunum end-to-side; all stitches were retained and organized, and the knots were gently tied. The jejunum was then opened on its antimesenteric side, next to the mesentery, and the mucosa was sutured on the cut edge of the pancreas with interrupted sutures with integration of previously posterior placed ductal sutures; all knots were tied after completion of the inner posterior suture. The anterior inner suture between the anterior cut edge of pancreas and the opened jejunum was performed utilizing the previously placed anterior ductal suture. The second row of anterior suture covered the inner suture line without tension and invaginated the anterior cut edge into the jejunum by $1 \mathrm{~cm}$.

Then, an end-to-side hepaticojejunostomy with interrupted single sutures PDS 5.0 was performed.

In selected cases, we used the round ligament as a patch around the PJ anastomosis, as described by lannitti et al. [12].

In both group $1^{\circ}$ and $2^{\circ}$, surgical loupes were routinely used at $2.5 \times$ magnification for pancreaticojejunal anastomosis; in two cases, a microscope at $12.5 \times$ was used.

Digestive continuity was restored by an ante-colic duodenal/gastro-jejunostomy in classic Whipple with a Braun anastomosis or a Roux-en-Y in five patients. One (or two) $4 \times 10 \mathrm{~mm}$ fluted flat drainages were placed behind the pancreatic and biliary anastomosis, and the postoperative secretion was routinely monitored with respect to amylase contents. A nutritional jejunostomy was placed $20 \mathrm{~cm}$ next to the last jejunal anastomosis and utilized from the second postoperative day [13].

In case of cancer, lymph node dissection along the hepatoduodenal ligament, common hepatic artery, vena cava, superior mesenteric vein and the right side of the superior mesenteric artery was a standard part of the procedure. Octreotide was started during the induction of anaesthesia and given for some days after operation (three doses of 0.1-0.2 mg per day subcutaneously).

\section{Endpoint}

The aim of the present study was to compare rates of clinically relevant POPF using the last classification proposed by ISGPS [8] in two groups of patients, before and after introduction of a different technique for pancreaticojejunal anastomosis. Morbidity and mortality were also evaluated. 


\section{Statistical analysis}

Statistical analysis was done by addressing differences in categorical variables between the two groups with Chi square test for $2 \times 2$ contingency tables. Fisher's exact test was used when the number of an observed value was $<5$. For continuous variables, a two-tailed t-test was used, and $P$ values $<0.05$ were considered statistically significant.

Statistical analyses were performed using MedCalc for Windows, version 11.6 (MedCalc Software, Ostend, Belgium).

\section{Results}

Results were retrospectively analysed in terms of postoperative mortality and morbidity (Table 2).

Mortality was defined as death within 30 days or in hospital, irrespective of the duration of stay. The definition of CR-POPF was based on the consensus classification of the International Study Group of Pancreatic Surgery (ISGPS) [8]; for the delayed gastric emptying (DGE) and Postpancreatectomy haemorrhage (PPH), we referred to ISGPS classification $[14,15]$.

\section{Mortality:}

In group $1^{\circ}$, the mortality rate was $2,8 \%(2 / 71)$. One patient died of perioperative haemorrhagic shock, and the second died three months after PD after delayed sentinel haemorrhage from POPF C, reoperation with total pancreasectomy, discharge and readmission for uncontrolled diabetes and herpes virus disease. Zero mortality was observed in group $2^{\circ}$.

\section{Morbidity:}

As reported by a grading system applied to pancreaticoduodenectomy [16], we also assessed grade II-V Clavien-Dindo morbidity from one or more complications; $34 / 70$ patients $(48,5 \%)$ in group $1^{\circ}$ and $19 / 71$ patients $(26,7 \%)$ in group $2^{\circ}$ had these complications.

A total of 40 complications occurred in group $1^{\circ}$ and 22 in group $2^{\circ}$. Uneventful postoperative course (grade $0-1$ Clavien-Dindo) occurred in $51,5 \%$ and $73,7 \%$ of patients, respectively, in the two groups.

Wound infection, urinary tract infection, pneumonia and cholangitis were included as complications when there was the need for antibiotic treatment and/or when hospital stay was prolonged because of these complications, according to Clavien-Dindo classification [16, 17].

Clinically relevant POPF occurred in 12 patients in group $1^{\circ}(17 \%)$ and in 4 patients in group $2^{\circ}(5,6 \%), p=$ 0.06 . For POPF $B\left(10\right.$ in group $1^{\circ}$ and 3 in group $\left.2^{\circ}\right)$, an intraoperative drain was left for more than 3 weeks, except for one patient in the first group, for whom interventional drainage was used. 
Two patients had POPF $\mathrm{C}$ in group $1^{\circ}$; both underwent reoperation for sentinel bleeding from stump erosion of the gastroduodenal artery in post operative day (POD) 7 and POD 20, and one of these patients died.

In group $2^{\circ}$, one case of POPF C $(1,4 \%)$ was observed. Because of multiorgan failure, the patient was admitted to the Intensive care unit (ICU) and then discharged after 7 days.

PPH occurred in five patients (7\%) in group $1^{\circ}$ : two grade B and three grade C; 2 early and 3 delayed haemorrhage; and 1 intraluminal (treated with blood transfusions) and 4 extraluminal. Four subjects were submitted to re-laparotomy, in two cases for sentinel haemorrhage and POPF C. In group $2^{\circ}, \mathrm{PPH}$ occurred in two patients $(2,8 \%)$ : one grade $B$ and one grade $\mathrm{C}$; one early submitted to re-laparotomy, and one had delayed intraluminal haemorrhage treated with angiography and embolization.

Five patients suffered from DGE in both groups (7\%); one DGE C case in group $2^{\circ}$ was re-operated at POD 25 with Roux-en-Y. Prolonged enteral nutritional support through routinely placed jejuneostomy was performed and well tolerated; prolongation of hospital stay did not cause any delay of adjuvant therapy, as the patient was classified as TNM stage I.

Operative time was significantly higher in the second group. 
Table 2

Morbidity and mortality

\begin{tabular}{|c|c|c|c|}
\hline & Group $1^{\circ}(\%)$ & Group $2^{\circ}(\%)$ & p-value \\
\hline Mortality (30 day in hospital) & $2 / 71(2.8 \%)$ & $0 / 71$ & 0.496 \\
\hline Morbidity II-IV Clavien-Dindo pts & $34(48.5 \%)$ & $19(26.7 \%)$ & 0.009 \\
\hline Morbidity II-IV Clavien-Dindo ${ }^{\circ}$ & 40 & 22 & 0.002 \\
\hline POPF B & $10(14.2 \%)$ & $3(4.2 \%)$ & \\
\hline POPF C & $2(2.8 \%)$ & $1(1.4 \%)$ & \\
\hline CR-POPF total & $12(17 \%)$ & $4(5.6 \%)$ & 0.06 \\
\hline PPH B-C & $5(7 \%) 2 B, 3 C$ & $2(2.8 \%) 1 \mathrm{~B}, 1 \mathrm{C}$ & 0.44 \\
\hline DGE B-C & $5(7 \%) 4 \mathrm{~B}, 1 \mathrm{C}$ & $5(7 \%) 3 B, 2 C$ & 1 \\
\hline Biliary leakage & $1(1.4 \%)$ & $1(1.4 \%)$ & 1 \\
\hline Cardiopulmonary & $5(7 \%)$ & $4(5.6 \%)$ & 1 \\
\hline Infection (bile, wound, abscess) & $11(15.7 \%)$ & $5(7 \%)$ & 0.18 \\
\hline Khyle leak & $1(1.4 \%)$ & $1(1.4)$ & 1 \\
\hline Reoperation & $4(5.7 \%)$ & $2(2.8 \%)$ & 0.68 \\
\hline Operative time mean (SD) min & $366.9(\mathrm{SD} \pm 60.1)$ & $400.4(S D \pm 55.2)$ & $P<0.001$ \\
\hline Blood loss mean (SD) $\mathrm{ml}$ & $1040(S D \pm 1230)$ & $1020(S D \pm 1270)$ & $P=0.92$ \\
\hline LOS (length of stay-days) mean (SD) & $25(\mathrm{SD} \pm 11.6)$ & $18(S D \pm 9)$ & $P<0.001$ \\
\hline
\end{tabular}

\section{Discussion}

A standardized approach to the pancreatic anastomosis and a consistent practice of a single technique appear to be related to decreased postoperative complications [18].

The ISGPS in 2010, improving uniformity and standardization in pancreatic anastomosis (PA), formulated a new classification that incorporates factors related to the pancreatic remnant, such as pancreatic duct size, length of mobilization, and gland texture, as well as factors related to the pancreatoenteric anastomosis. The use of duct-to-mucosa anastomosis or invagination (dunking) of the remnant into the jejunum, the use of a stent (internal or external) across the anastomosis, and the use of intraperitoneal drains were other important issues discussed [19].

In 2017, an ISGPS position statement failed to provide definitive, consistent and convincing level 1 evidence that any PA technique was better than the others. Pancreaticojejunostomy (PJ) remains the 
most common type of reconstruction, practised by $88.7 \%$ of surgeons. [20]

Another issue of interest concerns the placement of trans-anastomotic stents. [21] Some authors reported that a normal soft pancreas does not require a stenting tube [22-24]. Ductal stents in pancreatic anastomosis were frequently used (47\%) in our group $1^{\circ}$ and in only one patient in group $2^{\circ}$. A biliary Ttube was inserted in $91 \%$ of patients in group $1^{\circ}$ and rarely $(7 \%)$ in group $2^{\circ}$, with the rationale that the diversion of biliary secretions away from pancreatic drainage may avoid activation of pancreatic enzymes and therefore protect the healing process of the PJ [25]. Other authors subsequently suggested reconstruction on dual loop (Roux-en-Y) [26, 27].

The use of routine drains at the site of the anastomosis has been widely debated [28, 29]; a randomized, prospective, multicenter trial demonstrated an increase number of complications and mortality in PD without intraperitoneal drainage [30]. Nevertheless, drains may provide access for bacteria, potentially leading to super infected fluid, bile, chyle, and pancreatic juice collections [31]. Lastly, a recent dual-centre randomized trial indicated that selective drainage might be a better concept; abandoning intraperitoneal drains did not increase the reintervention rate, mortality, and overall morbidity. Moreover, the clinically relevant POPF rate was lower in the no-drain group (CR-B/C 11,9\% vs 5,7\%)[32].

Furthermore, management decisions involve the postoperative day of drain removal. Even the timing of drain removal is still under discussion. In a report on 1.507 patients with PD, drain removal occurred at median POD 7 [6]; in contrast, in patients with a low risk of pancreatic fistula, intra-abdominal drains can be safely removed on POD 3 or POD 1 after standard pancreatic resections [33-35]. A prolonged period of drain insertion was associated with a higher rate of postoperative complications with increased hospital stay and costs $[36,37]$. We routinely used drains in group $1^{\circ}$ patients without POPF, removing the drain on POD 7; in low risk group $2^{\circ}$ patients, we removed drain earlier, on POD 3.

Preoperative biliary drainage (PBD) does not have a beneficial effect on postoperative outcome; intraoperative bile samples had demonstrated that contamination of bile was significantly increased in patients who underwent stenting, as recently reported [38]. The increase of postoperative overall complications and wound infections urges precise indications for preoperative biliary drainage [39, 40]. Our experience showed many infections (biliary and wound) in patients with preoperative biliary drainage (nearly half of patients).

Vascular resection, especially performed in group $2^{\circ}$, did not increase the complication rate of our patients, as other authors reported, but justified a small increase in operative time and blood loss [41, 42]. Mortality rates (30 days or in hospital) varied in most recent publications between $2 \%$ and $4 \%[2,3,43,44$, 45]. Volume-outcome relationships in pancreaticoduodenectomy are well established, but an optimal volume remains to be determined. Mortality at 90 postoperative days was most favourable in $>40$ PDs/year centers compared with 5-19 PDs/year centres (4,3\% vs 8,9\%) [46]. In our centre, the volume of pancreatic resection was lower (14.6 /year) but with high volume of major oncological surgery; our mortality rate of 30 days or in hospital was $2,8 \%(2 / 71)$ in group $1^{\circ}$ and zero in group $2^{\circ}(0 / 71)$. Morbidity 
rates after pancreaticoduodenectomy remain high, between $30-50 \%$, as documented in several studies $[1,3,4,32,44,45,47]$.

The rate of clinically relevant postoperative pancreatic fistula (CR-POPF) in PJ continues to range between $10 \%$ and $15 \%$ [48-52]. In a recent, multicenter, multinational report of $>4000$ pancreaticoduodenectomies, CR-POPFs occurred in $11.1 \%$ of all cases [53]. In 2016, from the Heidelberg centre, there was a proposal to assign all patients undergoing interventional drainage as POPF grade B. Among 1889 PD, the clinically relevant POPF rate was 8,9\% (4,8\% B and 4,1\% C) [7]. Then, 11 years after the 2005 Consensus, ISGPS redefined grade A postoperative pancreatic fistula as "biochemical leak". Grade B POPF requires a change in the postoperative management: drains should be left in place for more than 3 weeks or repositioned through endoscopic or percutaneous procedures. Grade C POPF refers to those conditions that require reoperation or lead to single or multiple organ failure or death [8].

The decrease in CR-POPF from $17-5.6 \%$ in our experience is probably due to standardization and meticulous attention to technical details. The use of fine monofilament sutures with fine needles could also reduce tissue damage, improving postoperative outcomes.

Certainly the absence of routine detection of pancreatic texture constituted a lack of the study.

The inability to tolerate a solid diet by POD 7 should be considered as DGE, occurring in $14 \%-21 \%$ of patients after PD with prolonged hospitalization $[1,3,4,45]$. The consensus definition of DGE after pancreatic surgery without mechanical obstruction was reached in 2007 by ISGPS and classified into Grades A, B and C [17]. As others author reported, in PPPD we always performed a dilatation of the pylorus with farabeuf until calibration to $26 \mathrm{~mm}$ [54].

PPH occurs in $1-8 \%$ of all pancreatic resection and represents from $11-18 \%$ of overall mortality $[45,47$, 55]. In the literature, it was defined on the basis of 3 criteria: time of onset (early PPH occurring in the first 24 hours and late PPH occurring after $24 \mathrm{~h}$ postoperative), location (intra or extraluminal), cause and severity. In 2007, ISGPS proposed classifying PPH as A, B and C [15].

Reoperation is life-threatening: its rate was reported to be between $2,7 \%$ and $8 \%[1,3,7,48,56]$. In our experience, the overall reoperation rate was $(5,7 \%)$ in group $1^{\circ}$ and $2,8 \%$ in group $2^{\circ}$. Mortality for all reoperations was $16,6 \%(1 / 6)$.

Several authors reported operation time, blood loss and length of stay as features of surgery $[32,45,48]$. In our experience, operative time was longer in group $2^{\circ}(P<0,001)$, perhaps for more time to perform pancreaticojejuneal anastomosis and probably due to vascular resection. Length of stay was decreased in group $2^{\circ}(P<0,001)$ because of lower numbers of complications, especially POPF.

\section{Conclusion}

In conclusion, the comparison between two groups of patients with different pancreatico-jejuneal anastomosis showed a lower rate of clinically relevant POPF and lower morbidity, mortality and length of 
stay in the second group of patients.

Although it is a long period of study observation, it seems that the reduction of fistulas is mainly dependent on the type of anastomosis rather than other factors.

We consider this technique to be safe and reproducible by other surgeons through an educational surgical program.

The standardization of technical surgical details and careful perioperative care are crucial aspects, in our experience.

Furthermore, we believe, like Traverso, that "surgery alone is not sufficient" for pancreatic cancer [57]. The goal is to avoid morbidity, as the best candidate for adjuvant treatment will be that patient who has no delay in postoperative recovery.

\section{List Of Abbreviations}

CR-POPF Clinically relevant postoperative pancreatic fistula

PD Pancreaticoduodenectomy

ISGPF International Study Group of Pancreatic Fistula

ISGPS International Study Group of Pancreatic Surgery

PPPD Pylorus preserving pancreaticoduodenectomy

PBD Preoperative biliary drainage

PDS Polydioxanone

PPH Postpancreatectomy haemorrhage

DGE Delayed gastric emptying

POD Post operative day

TNM Tumor nodes metastasis

ICU Intensive care unit

PA Pancreatic anastomosis

PJ Pancreaticojejunostomy

\section{Declarations}


All procedures performed in studies involving human participants were in accordance with the ethical standards of the institutional and/or national research committee and with the 1964 Helsinki declaration and its later amendments or comparable ethical standards. This retrospective study did not need the approval of the ethics committee. Written informed consent was obtained from all patients before surgery.

\section{Consent for publication}

Not applicable

\section{Availability of data and materials}

The datasets used and/or analysed during the current study are available from the corresponding author on reasonable request

\section{Competing interests}

The authors declare that they have no competing interests.

\section{Funding}

No funding has been received for this study.

\section{Acknowledgements}

Not applicable

\section{Author contributions}

TZ, SO and FZ designed the study, TZ, SO and LM contribuited to data acquisition and analysis, TZ, SO and FZ were involved in interpretation of data and writing of the paper, FZ and TZ critically revised the manuscript.

All authors have read and approved the manuscript.

\section{References}

1. Cameron JL, Riall TS, Coleman JA, Belcher KA. One thousand consecutive pancreaticoduodenectomies. Ann Surg. 2006;244:10-7. DOI:10.1097/01.sla.0000217673.04165.ea.

2. Buchler MW, Friess $\mathrm{H}$, Wagner M, Kulli C, Wagener V, Z'graggen K. Pancreatic fistula after pancreatic resection. Br J Surg. 2000;87:882-9. DOI:10.1046/j.1365-2168.2000.01465.x. PMID: 10931023. 
3. Buchler MW, Wagner M, Schmied BM, Uhl W, Friess H, Z'graggen K. Changes in Morbidity After Pancreatic Resection. Toward the end of Completion Pancreatectomy. Arch Surg. 2003;138:1310-4. DOI:10.1001/archsurg.138.12.1310. PMID: 14662530.

4. Butturini G, Marcucci S, Molinari E, Mascetta G, Landoni L, Crippa S, Bassi C. Complication after pancreaticoduodenectomy: the problem of current definition. J Hepatobiliary Pancreat Surg. 2006;13:207-11. DOI 10.1007/s00534-005-1035-7. PMID: 16708296.

5. Bassi C, Dervenis C, Butturini G, Fingerhut A, Yeo C, Izbicki J, Neoptolemos J, Sarr M, Traverso W, Buchler MW. Postoperative pancreatic fistula: An International Study Group (ISGPF) definition. Surgery. 2005;138:8-13. DOI:10.1016/j.surg.2005.05.001. PMID:16003309.

6. Reid-Lombardo KM, Farnell MB, Crippa S, Bernett M, Moupin G, Bassi C, Traverso W. Pancreatic anastomotic leakage after pancreaticoduodenectomy in 1,507 patients: a report from the Pancreatic Anastomotic Leak Study Group. J Gastrointest Surg. 2007;11:1451-8. DOI:10.1007/s11605-0070270-4. discussion 1459. PMID:17710506.

7. Hackert T, Hinz U, Pausch T, Fesenbeck I, Strobel O, Schneider L, Fritz S, Buchler MW. Postoperative pancreatic fistula: we need to redefine grades B and C. Surgery. 2016;159:872-7. http://dx.doi.org/10.1016/j.surg.2015.09.014.

8. Bassi C, Marchegiani G, Dervenis C, Sarr MD. M et al. The 2016 update of the International Study Group (ISGPS) definition and grading of postoperative pancreatic fistula: 11 Years After. Surgery. 2017;161:584-91.

9. Z'graggen K, Uhl W, Friess H. and Büchler MW. How to do a safe pancreatic anastomosis. J Hepatobiliary Pancreat Surg. 2002;9:733-7.

10. Shrikhande SV, Kleeff J, Buchler MW, Friess H. Pancreatic anastomosis after pancreaticoduodenectomy: how we do it. Indian J Surg. 2007;69:224-9.

11. Longmire WP, Traverso LW. The Whipple Procedure and Other Standard Operative Approach to Pancreatic Cancer. Cancer. 1981;47:1706-11.

12. Iannitti DA, Coburn NG, Somberg J, Ryder BA, Monchik J, Cioffi WC. Use of the Round Ligament of the Liver to Decrease Pancreatic Fistulas: A Novel Technique. J Am Coll Surg. 2006;203:857-64.

13. Malleo G, Pulvirenti A, Marchegiani G, Butturini G, Salvia R, Bassi C. Diagnosis and management of postoperative pancreatic fistula. Langenbecks Arch Surg. 2014;399:801-10.

14. Wente MN, Bassi C, Dervenis C, Fingerhut A, Sarr M, Traverso LW, Yeo CJ, Buchler MW, et al. Delayed gastric emptying (DGE) after pancreatic surgery: A suggested definition by the International Study Group of Pancreatic Surgery (ISGPS). Surgery. 2007;142:761-8.

15. Wente MN, Veit JA, Bassi C, Dervenis C, Fingerhut A, Neoptolemos JP, Sarr M, Yeo CJ, Buchler MW, et al. Postpancreatectomy hemorrhage (PPH) - An International Study Group of Pancreatic Surgery (ISGPS). 2007 Surgery,142: 20-25.

16. DeOliveira ML, Winter JM, Schafer M, Cunningham SC, Cameron JL, Yeo CJ, Clavien PA, et al. Assessment of Complication After Pancreatic Surgery. A Novel Grading System Applied to 633 Patients Undergoing Pancreaticoduodenectomy. Ann Surg. 2006;244:931-9. 
17. Clavien PA, Barcun J, DeOliveira ML, Dindo D, Bassi C, Cameron JL, et al. The Clavien-Dindo Classification of Surgical Complication. Five-Years Experience. Ann Surg. 2009;250:187-96.

18. Shrikhande SV, Barreto G, Shukla PJ. Pancreatic fistula after pancreaticoduodenectomy: the impact of standardized technique of pancreaticojejunostomy. Langenbecks Arch Surg. 2008;393:87-91.

19. Shukla PJ, Barreto SG, Fingerhut A, Bassi C, Buchler MW, et al. Toward improving uniformity and standardization in the reporting of pancreatic anastomoses: A new classification system by the International Study Group of Pancreatic Surgery (ISGPS). Clincal Review Surgery. 2010;147:144-53.

20. Shrikhande SV, Sivasanker M, Vollmer CM, Friess H, et al. Pancreatic anastomosis after pancreatoduodenectomy: A position statement by the International Study Group of Pancreatic Surgery (ISGPS). Surgery. 2017;161:1221-34.

21. McMillan M, Malleo G, Bassi C, Sprys MH, Vollmer CM Jr. Defining the practice of pancreatodudenectomy around the world. J Hepatobiliary Pancreat Surg. 2015;17:1145-54.

22. Imaizumi T, Hatori T, Tobita K, Fukuda A, Takasaki K, Makuuchi H. Pancreaticojejunostomy using duct-to-mucosa anastomosis without a stenting tube. J Hepatobiliary Pancreat Surg. 2006;13:194201.

23. Xiong JJ, Altaf K, Mukherjee R, Huang W, Hu WM, Li A, Ke NW, Liu XB. Systematic review and metaanalysis of outcomes after intraoperative pancreatic duct stent placement during pancreaticoduodenectomy. Br J Surg. 2012;99:1050-61.

24. Winter JM, Cameron JL, Campbell KA, Chang DC, Riall TS, Schulick RD, et al. Does pancreatic duct stenting decrease the rate of pancreatic fistula following pancreaticoduodenectomy? Results of a prospective randomised trial. J Gastrointest Surg. 2006;10:1280-90.

25. Nakamura T, Okada A, Higaki J, Tojo H, Okamoto M. Pancreaticobiliary maljunction-associated pancreatitis: an experimental study on the activation of pancreatic phospholipase A2. World J Surg. 1996;20:543-50.

26. Machado MCC, Machado MAC. Systematic use of isolated pancreatic anastomosis after pancreatoduodenectomy: Five years of experience with zero mortality. EJSO 2016.05.023Aviable online.

27. Klaiber U, Probst P, Knebel P, Contin P, Diener MK, Buchler MW, Hackert T. Meta-analysis of complication rates for single-loop versus dual-loop (Roux-en-Y) with isolated panctreaticojejunostomy reconstruction after pancreaticoduodenectomy. BJS. 2015;102:331-40.

28. Heslin MJ, Harrison LE, Brooks AD, Hochwald SN, Coit DG, Brennan MF. Is intra-abdominal drainage necessary after pancreaticoduodenectomy? J Gastrointest Surg. 1998;2:373-8.

29. Conlon KC, Labow D, Leung D, Smith A, Jarnagin W, Coit DG, Merchant N, Brennan MF. Prospective randomized clinical trial of the value of intraperitoneal drainage after pancreatic resection. Ann Surg. 2001;234:487-93.

30. Van Buren G, Bloomston M, Hughes S, Winter J, et al. A Randomized Prospective Multicenter trial of Pancreaticodudenectomy With and Without Routine Intraperitoneal Drainage. Ann Surg. 2013;00:18. 
31. 32. Giovinazzo F, Butturini G, Salvia R, et al. Drain management after pancreatic resection: state of the art. J Hepatobiliary Pancreat Surg 2011;18:779-84.

32. Witzigmann H, Diener MD, Buchler MW, et al. No Need for Routine Drainage After Pancretic Head Resection: The Dual-Center, Randomized, Controlled PANDRA Trial. Ann Surg. 2016;264:528-37.

33. Molinari E, Bassi C, Salvia R, Butturini G, Crippa S, Talamini G, Falconi M, Pederzoli P. Amylase Value in Drains After Pancreatic Resection as Predictive Factor of Postoperative Pancreatic Fistula. Results of a Prospective Study in 137 patients. Ann Surg. 2007;246:281-7.

34. Lu X, Wang X, Fang Y, Chen H, Peng C, Li H, et al. Systematic Review and Meta-Analysis of Pancreatic Amylase Value on Postoperative Day 1 After pancreatic Resection to predict Postoperative Pancreatic Fistula. Medicine. 2016;5:1-10.

35. Bertens KA, Crown A, ClantonJ, Allemi F, Alseidi AA, Biehl T, Helton WS, Rocha FG. What is the better predictor of clinically relevant postoperative pancreatic fistula (CR-POPF) following pancreaticoduodenectomy (PD): postoperative day one drain amylase (POD1A) or the fistularisk score (FRS)? J Hepatobiliary Pancreat Surg. 2017;19:75-81.

36. Bassi C, Molinari E, Malleo G, Crippa S, Butturini G, Salvia R, Talamini G, Pederzoli P. Early Versus Late Remove Drain Removal After Standard Pancreatic Resection. Results of a Prospective Randomized Trial. Ann Surg. 2010;252:2017-214.

37. Fong ZV, Correa-Gallego C, Ferrone C, Veillette GR, Warshaw AL, Lillemoe KD, Fernandez-del Castillo C. Early Drain Removal-The Middle Ground Between the Drain Versus No Drain Debate in Patients Undergoing Pancreaticoduodenectomy. A Prospective Validation Study. Ann Surg. 2015;262:378-83.

38. Scheufele F, Aichinger L, Jager C, Demir IE, et al. Effect of preoperativebiliary drainage on bacterial flora in bile of patients with periampullary cancer. BJS. 2017;104:e182-8.

39. Van der Gaag NA, Rauws EAJ, Van Eijck CHJ, Bruno MJ, et al. Preoperative Biliary Drainage for Cancer of the Head of the Pancreas. N Engl J Med. 2010;362:129-37.

40. 10.1016/j.surg.2016.11.001

Scheufele F, Schorn S, Demir IE, Sargut M, et al. Preoperative biliary stenting versus operation first in jaundiced patients due to malignant lesion in the pancreatic head: A meta-analysis of current literature. Surgery 2016 in press. http://dx.doi.org/10.1016/j.surg.2016.11.001.

41. Tseng JF, Raut CP, Lee JL, Pisters PWT, Vauthey JN, Abdalla EKA, Gomez HF, Sun C, Crane CH, Wolff RA, Evans DB. Pancreaticoduodenectomy With Vascular Resection: Margin Status and Survival Duration. J Gastroint Surg. 2004;8:935-50.

42. Weitz J, Kienle P, Schmidt J, Friess H, Buchler M. Portal Vein Resection for Advanced pancreatic Head cancer. J Am Col Surg. 2007;204:712-6.

43. Trede M, Saeger HD, Schwall G, Rumstadt B. Resection of pancreatic cancer - surgical achievements. Langenbeck's Arch Surg. 1998;383:121-8.

44. Addeo P, Delpero JR, Paye F, Oussoultzoglou E, Fuchshuber PR, Sauvanet A, et al. Pancreatic fistula after a pancreaticoduodenectomy for ductal adenocarcinoma and its association with morbidity: a multicenter study of the. French Surgical Association HPB. 2014;16:46-55. 
45. Cameron JL, He J. Two Thousand Consecutive Pancreaticoduodenectomies. J Am Coll Surg. 2015;220:530-6.

46. Van der Geest LGM, Van Rijssen LB, Molenaar IQ, De Hingh I, Bas Grot Koerkamp, Busch ORC, et al. Volume-outcome relationships in pancreatoduodenectomy for cancer. HPB 2016;18: 317-324.

47. Harnoss JC, Ulrich AB, Harnoss JM, Diener MK, Buchler MW, Welsch T. Use and results of consensus definition in pancreatic surgery:A systematic review. Surgery. 2014;155:47-57.

48. Braga M, Capretti G, Pecorelli N, Balzano G, Doglioni C, Ariotti R Di. Carlo V. A Prognostic Score to Predict Major Complication after Pancreaticodudenectomy. Ann Surg. 2011;254:702-8.

49. Pratt W, Maithel SK, VanounouT, Callery MP, Vollmer CM Jr. Postoperative Pancreatic Fistula Are Not Equivalent After Proximal, Distal and Central Pancreatectomy. J Gastrointest Surg. 2006;19:126479.

50. Hashimoto Y, Taverso LW. Incidence of pancreatic anastomotic failure and delayed gastri emptying after pancreatoduodenectomy in 507 patients: Use of a web-based calculator to improve homogeneity of definition. Surgery. 2010;147:503-15.

51. Ansorge C, Nordin JZ, Lundell L, Strommer L, et al. Diagnostic value of abdominal drainage in individual risk assessment of pancreatic fistula following pancreaticoduodenectomy. BJS. 2014;101:100-4.

52. Hiyoshi M, Chijiiwa K, Fujii Y, Inamura N, et al. Usefulness of Drain Amylase, Serum C-Reactive Protein Levels and Body Temperature to Predict Postoperative Pancreatic Fistula After Pancreaticoduodenectomy. World J Surg. 2013;37:2436-42.

53. McMillan MT, Sammer Soi BA, Asbun H, Ball CG, Bassi C, et al. Risk-adjusted Outcomes of Clinically Relevant Pancreatic Fistula Following Pancreatoduodenectomy: A Model for performance Evaluation. Ann Surg. 2016;264:344.352.

54. Fischer $\mathrm{CP}$, Hong JC. Method of pyloric reconstruction and impact upon delayed gastric emptying and hospital stay after pylorus-preserving pancreaticoduodenectomy. J Gastrointest Surg. 2006;10:215-9.

55. Grutzmann R, Ruckert F, Hippe-Davies N, Distler M, Saeger HD. Evaluation of the Internationl Study Group of Pancreatic Fistula definition of post-pancreatectomy hemorrhage in high-volume center. Surgery. 2012;151:612-20.

56. Balzano G, Pecorelli N, Piemonti L, Ariotti R, Carvello M, Nano R, Braga M, Staudacher C. Relaparotomy for a pancreatic fistula after pancreaticoduodenectomy: a comparision of different surgical strategies. HPB. 2014;16:40-5.

57. Traverso LW. Pancreatic cancer: surgery alone is not sufficient. Surg Endosc. 2006;20:446-9.

\section{Figures}


A

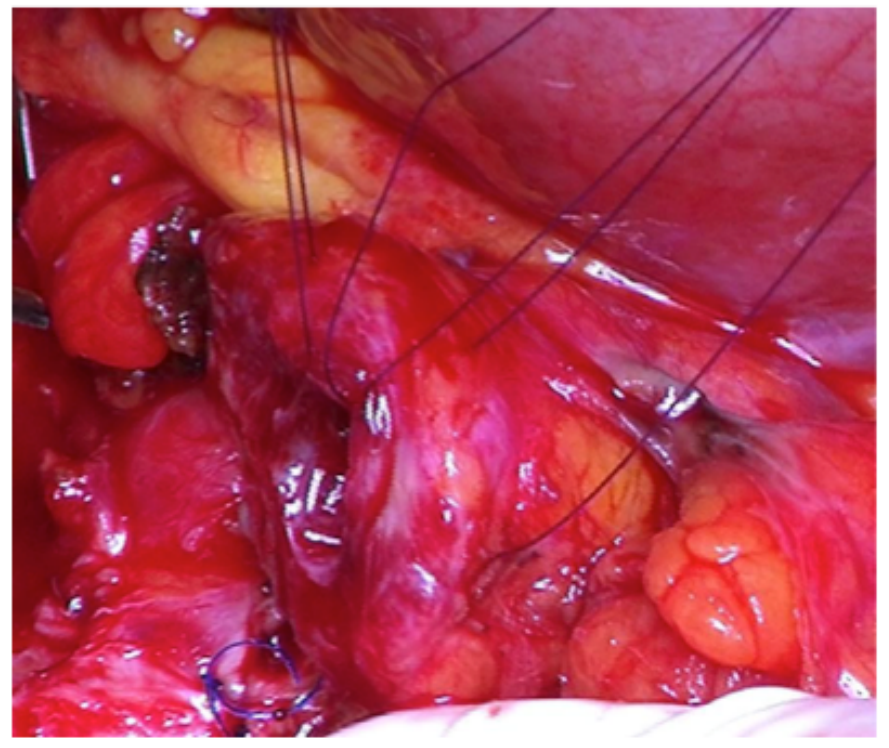

B

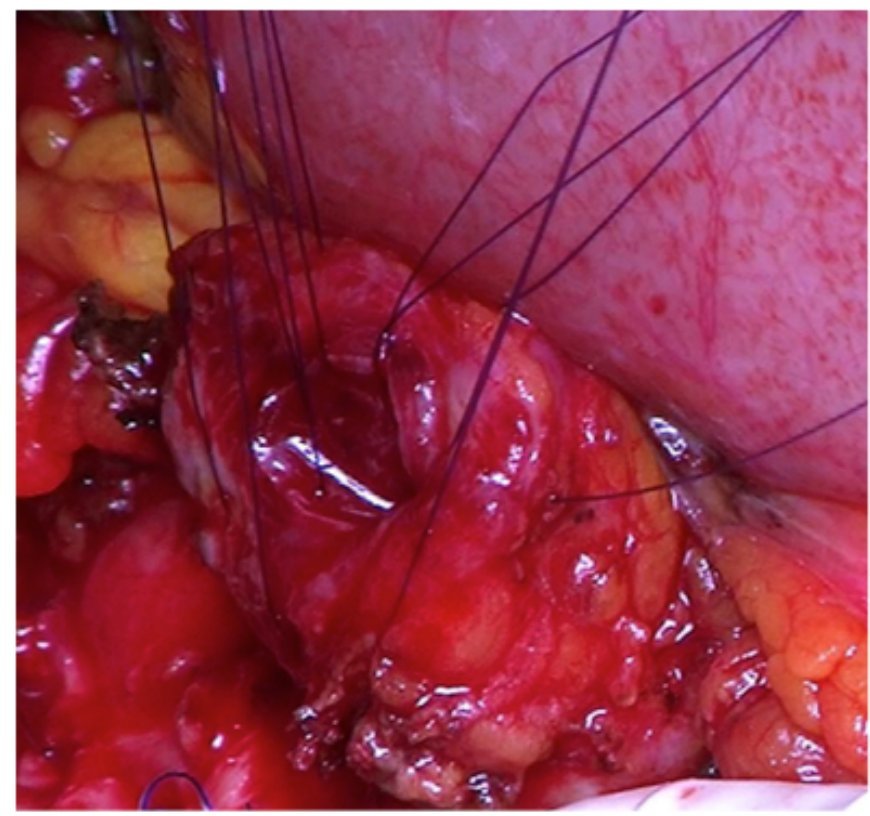

\section{Figure 1}

a: Anterior ductal sutures. b: Posterior ductal sutures.

A

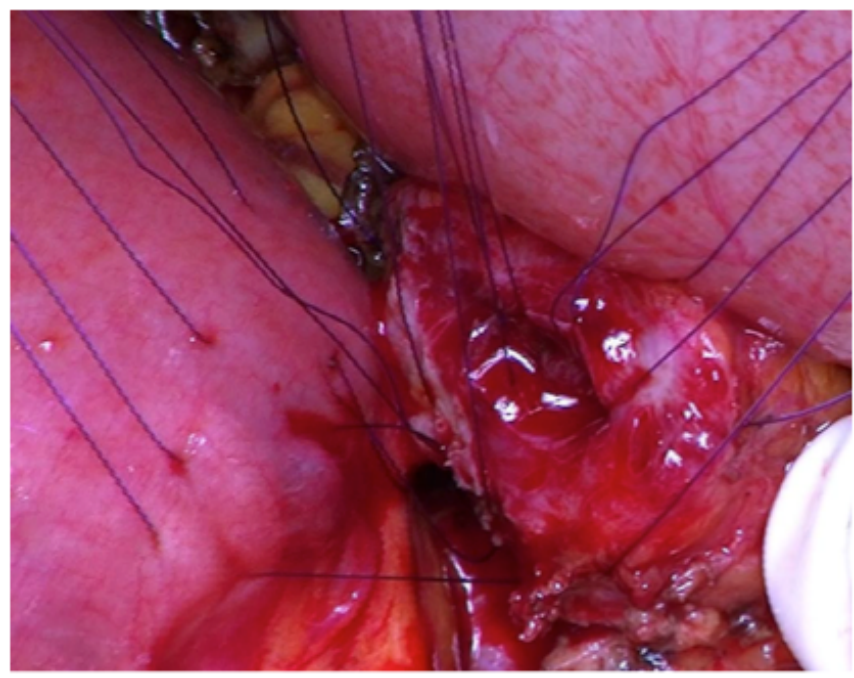

$\mathrm{B}$

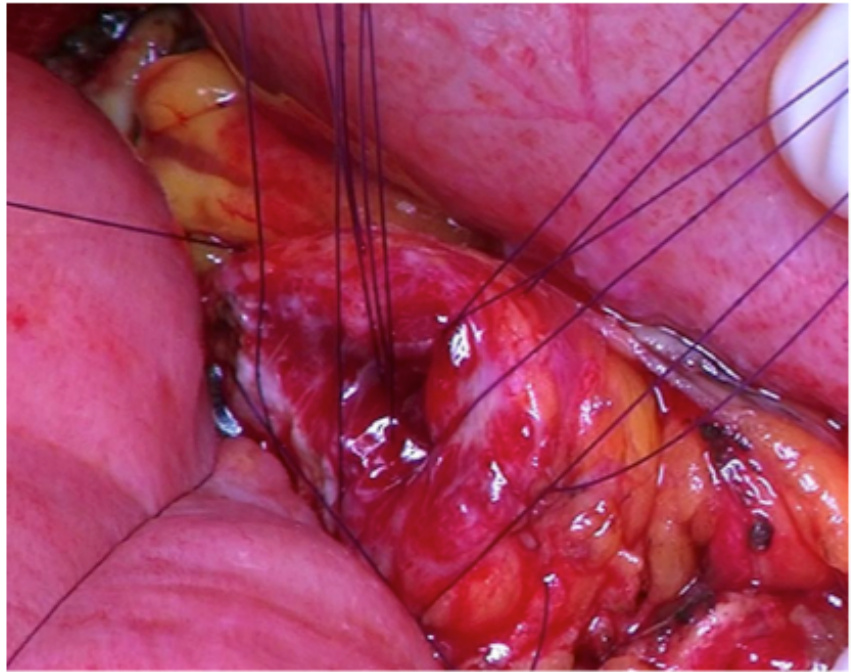

Figure 2

a: Posterior outer layer. b: Posterior outer layer completed. 
A

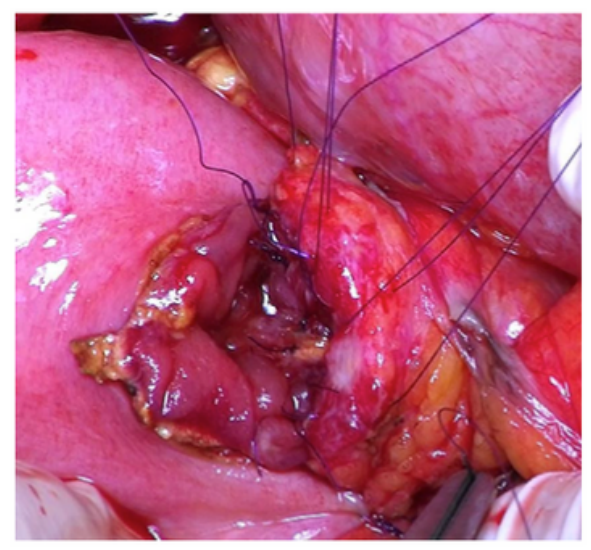

$\mathrm{B}$

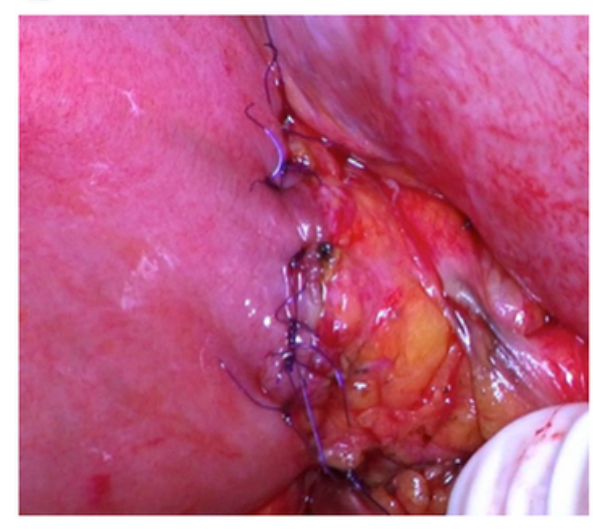

$\mathrm{C}$

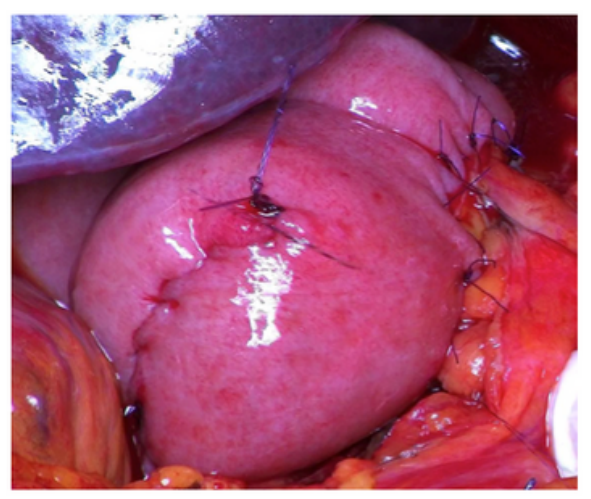

Figure 3

a: Posterior inner layer. b: Anterior inner layer. c: Completed anastomosis with anterior outer layer. 